\title{
Correction to: Implementation of machine learning algorithms to create diabetic patient re-admission profiles
}

\author{
Mohamed Alloghani ${ }^{1,2 *}$, Ahmed Aljaaf ${ }^{2,3}$, Abir Hussain², Thar Baker ${ }^{2}$, Jamila Mustafina $^{4}$, Dhiya Al-Jumeily ${ }^{2}$ and \\ Mohammed Khalaf
}

\section{Correction to: BMC Med Inform Decis Mak 19, 253 (2019) https://doi.org/10.1186/s12911-019-0990-x}

In the publication of this article [1], there were two errors.

The error: Authors Ahmed Aljaaf ${ }^{1,3}$, Abir Hussain ${ }^{1}$, Thar Baker ${ }^{1}$, and Dhiya Al-Jumeily ${ }^{1}$ are affiliated with affiliation 1 .

It should instead read: Ahmed Aljaaf ${ }^{2,3}$, Abir Hussain ${ }^{2}$, Thar Baker ${ }^{2}$, and Dhiya Al-Jumeily ${ }^{2}$ since the authors should instead be affiliated with affiliation 2: Computer science Department, Liverpool John Moores University, Liverpool, UK.

The error: the Acknowledgements section lacks additional acknowledgements.

It should instead read:

\section{Acknowledgments}

Dr. Mohamed Alloghani is an Advisor for the Minister of State for Artificial Intelligence in the United Arab Emirates and working at the Artificial Intelligence Office, Dubai. The data sources used in the paper was retrieved from UCI Machine Learning Repository as submitted by the Center for Clinical and Translational Research. The organization and the characteristics of the data made it easy to complete classification and clustering tasks. The authors would like to thank the eSystems
Engineering Society for the support provided to the work presented in this paper.

This has now been updated in this correction article.

\section{Author details}

${ }^{1}$ Artificial Intelligence Office, Dubai, UAE. ${ }^{2}$ Liverpool John Moores University, Computer science Department, Liverpool, UK. ${ }^{3}$ The University of Anbar,

Al-Tameem Street, Al-Anbar, Al-Ramadi 55431, Iraq. ${ }^{4}$ Kazan Federal University, Kremlyovskaya St, 420008 Kazan, Republic of Tatarstan, Russia. ${ }^{5}$ Department of Computer Science, Al-Maarif University College, Anbar, The city of Ramadi 31001, Iraq.

Published online: 18 May 2020

\section{Reference}

1. Alloghani M, Aljaaf A, Hussain A, et al. Implementation of machine learning algorithms to create diabetic patient re-admission profiles. BMC Med Inform Decis Mak. 2019;19(Suppl 9):253 https://doi.org/10.1186/s12911-019-0990-X.

\footnotetext{
The original article can be found online at https://doi.org/10.1186/s12911019-0990-x.

*Correspondence: phdmn2015@gmail.com

'Artificial Intelligence Office, Dubai, UAE

¿2Liverpool John Moores University, Computer science Department, Liverpool, UK

Full list of author information is available at the end of the article
}

(c) The Author(s). 2020 Open Access This article is licensed under a Creative Commons Attribution 4.0 International License, which permits use, sharing, adaptation, distribution and reproduction in any medium or format, as long as you give appropriate credit to the original author(s) and the source, provide a link to the Creative Commons licence, and indicate if changes were made. The images or other third party material in this article are included in the article's Creative Commons licence, unless indicated otherwise in a credit line to the material. If material is not included in the article's Creative Commons licence and your intended use is not permitted by statutory regulation or exceeds the permitted use, you will need to obtain permission directly from the copyright holder. To view a copy of this licence, visit http://creativecommons.org/licenses/by/4.0/ The Creative Commons Public Domain Dedication waiver (http://creativecommons.org/publicdomain/zero/1.0/) applies to the data made available in this article, unless otherwise stated in a credit line to the data. 